\title{
Immune Mechanisms Underlying the Beneficial Effects of Autologous Hematopoietic Stem Cell Transplantation in Multiple Sclerosis
}

\author{
David Gosselin • Serge Rivest
}

Published online: 9 September 2011

(C) The American Society for Experimental NeuroTherapeutics, Inc. 2011

\begin{abstract}
A recent phase I/II clinical trial drew serious attention to the therapeutic potential of autologous hematopoietic stem cell transplantation (AHSCT) in multiple sclerosis. However, questions were raised as to whether these beneficial effects should be attributed to the newly reconstituted immune system per se, or to the lymphoablative conditioning regimeninduced immunosuppression, given that T-cell depleting combinational drug therapies were used in the study. We discuss here the possibility that both AHSCT and T-cell depleting therapies may re-program alternatively the immune system, and why transplantation of $\mathrm{CD} 34^{+}$hematopoietic stem cells may offer AHSCT a possible advantage regarding longterm remission.
\end{abstract}

Keywords Autologous hematopoietic stem cell transplantation $\cdot$ Lymphoablation $\cdot$ Multiple sclerosis $\cdot \mathrm{T}$ cells

\section{Introduction}

Autologous hematopoietic stem cell transplantation (AHSCT) recently emerged as a promising alternative approach to treat patients suffering from multiple sclerosis (MS) refractory to classical immunomodulatory and immunosuppressive basedtherapies. Its application to treat MS stems from the premise that a dysregulated, autoreactive immune system could be

Electronic supplementary material The online version of this article (doi:10.1007/s13311-011-0062-0) contains supplementary material, which is available to authorized users.

D. Gosselin $\cdot$ S. Rivest $(\bowtie)$

Laboratory of Endocrinology and Genomics,

CHUQ Research Center and Department of Molecular Medicine,

Faculty of Medicine, Laval University,

Québec, Canada G1V 4G2

e-mail: serge.rivest@crchul.ulaval.ca eradicated and replaced by a new, tolerant one. To date, it has been applied not only for the treatment of MS, but also for other autoimmune diseases including type 1 diabetes, systemic lupus erythematosus (SLE) and systemic sclerosis [1-4]. With respect to MS, patients suffering from inflammation-associated relapsing-remitting MS and treated relatively early in the course of the disease respond better to AHSCT compared to those with long disease duration or those diagnosed with progressive MS. Although potentially hazardous, AHSCT safety has dramatically improved through the years, as the use of lymphoablative regimens has become increasingly prevalent at the expense of myeloablative strategies. Compared to myeloablation, lymphoablation presumably eliminates more selectively lymphocytes and lymphoid progenitors, and therefore minimizes irreversible toxicity to the hematopoietic cellular environment of the bone marrow. As such, it appears to allow for faster recovery and decreases the probability of hematologic and innate immunity complications [5-7].

Although the efficiency of AHSCT in MS is increasingly being validated [8], the immune mechanisms that account for its therapeutic effects are still largely unknown (see Table 1). Two basic hypotheses have been proposed to explain the beneficial effects of AHSCT. First, AHSCT may "reset" the immune system, yielding a novel, tolerant immune system. Tolerance could be achieved through 3 nonmutually exclusive mechanisms [9]: 1) elimination of the pre-AHSCT pathogenic T-cell lineage(s) [10]; 2) shifting of the pre-AHSCT autoreactive T-cell clones toward a tolerant phenotype [11], and 3) restoration of autoimmune inhibitory immunoregulatory effectors [12]. Yet, an alternative interpretation of the AHSCT data suggests that its clinical benefits might be attributed to the ability of the conditioning regimen to severely deplete Tcell populations for an extended time, thus inducing a state of long-lasting immunosuppression (see Table 2). This could be particularly true for AHSCT therapies that use an antibody- 
Table 1 Characteristics of the post-AHSCT immune system compared to pre-AHSCT status

\begin{tabular}{|c|c|c|c|c|}
\hline Reference & $\begin{array}{l}\text { Disease } \\
\text { Treated }\end{array}$ & Conditioning & $\begin{array}{l}\text { Follow-up } \\
\text { (years) }\end{array}$ & Primary Findings \\
\hline Muraro et al. [16] (2005) & MS & Myeloablative & 2 & $\begin{array}{l}\uparrow \text { Proportion naive } \mathrm{CD}^{+} \mathrm{T} \text { cells of thymic origin } \\
\downarrow \text { Proportion memory } \mathrm{CD} 4^{+} \mathrm{T} \text { cells } \\
\uparrow \mathrm{T} \text {-cell receptor repertoire and clonal diversity }\end{array}$ \\
\hline Sun et al. [19] (2004) & MS & Myeloablative & 1 & $\begin{array}{l}\text { No significant differences in phenotypic properties of } \mathrm{T} \text { cells } \\
\text { No significant differences in clonal diversity of } \mathrm{T} \text { cells }\end{array}$ \\
\hline Alexander et al. [18] (2009) & SLE & Lymphoablative & 4 (median) & $\begin{array}{l}\uparrow \text { Proportion naive } \mathrm{CD} 4^{+} \mathrm{T} \text { cells of thymic origin } \\
\uparrow \mathrm{T} \text {-cell receptor repertoire diversity } \\
\text { B-cell populations normalization } \\
\text { Elimination of autoantibodies }\end{array}$ \\
\hline Zhang et al. [9] (2009) & SLE & Lymphoablative & 2 (median) & $\begin{array}{l}\uparrow \mathrm{CD}^{+} \mathrm{FoxP}^{+} \text {TGF- } \beta \text {-producing Treg cells } \\
\uparrow \mathrm{CD}^{+} \mathrm{CD} 25^{\text {high }} \text { FoxP3 }^{+} \text {Treg cells }\end{array}$ \\
\hline
\end{tabular}

$\mathrm{AHSCT}=$ autologous hematopoietic stem cell transplantation; $\mathrm{MS}=$ multiple sclerosis; $\mathrm{SLE}=$ systemic lupus erythematosus; TGF=Transforming growth factor

mediated lymphoablative conditioning regimen. The validity of either hypothesis is currently a matter of debate in the field of MS and autoimmune diseases [13].

Based on human clinical studies, the purpose of the present discussion is twofold. First, we argue that a third hypothesis (i.e., namely that both therapies alternatively reprogram the immune system) also needs to be considered. Second, we discuss how transplantation of $\mathrm{CD} 34^{+}$hematopoietic stem cells (HSC) may be advantageous and critical to the establishment of a nonpathological immune system. It needs to be acknowledged that there are relatively scarce studies being conducted to investigate how the immune system specifically changes following AHSCT, largely because the application of AHSCT to treat MS is still in its beginnings. However, because MS is an autoimmune disease, it presents characteristics that often closely parallel those of other autoimmune diseases. Therefore, to substantiate the points made in this review, data generated in the AHSCT clinical trials in the context of other autoimmune diseases will be considered when appropriate. In addition, reviews have been written that focus more specifically on the clinical efficiency aspect of AHSCT in MS (for more detail, see Mancardi and Saccardi's [14] article from 2008 and Capello and colleagues' [15] from 2009).

Table 2 Characteristics of the immune system following alemtuzumab pulse

\begin{tabular}{|c|c|c|}
\hline Reference & Follow-up (years) & Primary Findings \\
\hline Cox et al. [23] (2005) & $\leq 0.5$ & $\begin{array}{l}\text { Lymphopenia } \\
\uparrow \text { Memory T-cell proportion within } \mathrm{CD}^{+} \mathrm{T} \text { pool } \\
\uparrow \mathrm{CD} 4+\mathrm{CD} 25^{\text {high }} \mathrm{T} \text { cells proportion within } \mathrm{CD} 4^{+} \mathrm{T} \text {-cell pool } \\
\text { Proliferation and level restoration of } \mathrm{B} \text { cell }\end{array}$ \\
\hline & 1 & $\begin{array}{l}\text { Normalization of the relative representation of T-cell subtypes } \\
\text { Persistent depletion in absolute number of } \mathrm{CD}^{+} \mathrm{T} \text { cells }\end{array}$ \\
\hline Jones et al. [33] (2009) & $0.25-0.75$ & $\begin{array}{l}\text { Lymphopenia } \\
\uparrow \mathrm{T} \text {-cell proportion responding to self-antigens } \\
\uparrow \mathrm{T} \text {-cell proliferation in response to self-antigens } \\
\uparrow \mathrm{T} \text {-cell passive and Fas-mediated apoptosis }\end{array}$ \\
\hline Thompson et al. [36] (2010) & $0.25-1$ & $\begin{array}{l}\text { Lymphopenia } \\
\text { Restoration and substantial expansion of B cells } \\
\uparrow \text { Serum B-cell activating factor (BAFF) }\end{array}$ \\
\hline
\end{tabular}




\section{AHSCT Mechanism of Action: Immune Reset Hypothesis}

In 2005, Muraro et al. [16] provided compelling evidence that AHSCT following myeloablation can reconfigure the immune system. In the peripheral $\mathrm{CD}^{+} \mathrm{T}$-cell population, the proportion of naive $\mathrm{CD} 45 \mathrm{RA}^{+} / \mathrm{CD} 45 \mathrm{RO}^{-} / \mathrm{CD} 27^{+} \mathrm{T}$ cells doubled 2 years after AHSCT relative to pretreatment assessment, whereas that of the $\mathrm{CD}^{2} 5 \mathrm{RA}^{-} / \mathrm{CD}^{2} 5 \mathrm{RO}^{+} /$ $\mathrm{CD} 27^{+}$central-memory T-cell subgroup decreased significantly by $38 \%$. CD 31 expression on $\mathrm{CD}^{+} / \mathrm{CD}^{2} 5 \mathrm{RO}^{-} \mathrm{T}$ cells in combination with preliminary data demonstrating an increase in T-cell receptor excision circles indicated a thymic ontogeny as opposed to an expansion in the peripheral T-cell compartment. Considering that thymic output diminishes as an individual ages [17], these data suggest a recovery of thymic functions in mature patients, leading to a rejuvenation of the $\mathrm{CD} 4{ }^{+} \mathrm{T}$-cell population.

Spectratyping analysis of the hypervariable complementarydetermining region 3 (CDR3) encoded within the $\beta$ chain of $T$ cell receptor (TCR) revealed a widened repertoire diversity within $\mathrm{CD}^{+} \mathrm{T}$ cells at the two-year follow-up compared to pretreatment. Sequencing analysis of the complementary determining region 3 at the single T-cell clone level estimated that for a majority of clones, $90 \%$ of the complementary determining region 3 analyzed were derived posttransplantation. $\mathrm{CD}^{+} \mathrm{T}$ cells also displayed a wider TCR repertoire following AHSCT. Therefore, it appears that through exhaustive clonal renewal, vast TCR rearrangements occur after AHSCT, leading to an augmentation of the T-cell repertoire and clonal diversity.

Similar observations on naive and central memory T cells, recent thymic emigrants, and TCR repertoire following AHSCT with SLE patients have also been reported by Alexander et al. [18]. Thus, not only do they corroborate the conclusions of Muraro et al. [16], but they also suggest that AHSCT has properties that are disease independent. Note, however, that an early AHSCT investigation did not report the same pre- $v s$ post-AHSCT immune differences. Indeed, in 2004, Sun et al. [19] concluded that the structural and functional phenotypes of reconstituted $\mathrm{T}$ cells postAHSCT were similar to those of pre-transplantation $\mathrm{T}$ cells. However, these data were obtained at a 1-year follow-up, whereas the effects in the Muraro et al. [16] and Alexander et al. [18] studies were observed for a span of 2 years following transplantation. Considering that $\mathrm{CD} 34^{+}$hematopoietic stem cell (HSC) grafts are not instantaneous, and that important expansion of the peripheral T-cell compartment takes place during the first 6 months following AHSCT [16], a 1-year follow-up period may have been insufficient for assessing an immune system reconfiguration that has yet to reach its equilibrium. Finally, no data regarding the functional phenotype of a rejuvenated immune system were reported by Muraro et al. [16]. Such data would be valuable, as defects in immunomodulatory mechanisms are potential etiological components of MS.

In 2009, Zhang et al. [9] reported evidence that AHSCT introduces or reintroduces immunoregulatory mechanisms. Although this study was performed with SLE patients, parallels with MS may possibly be drawn, given that both are autoimmune diseases. Patients underwent lymphoablative AHSCT and immune assays were performed on average 33 months after transplantation. Interestingly, immune phenotypes of transplanted patients were compared to those of healthy individuals and those of SLE patients treated with conventional therapies.

Zhang et al. [9] first compared the pre- and post-AHSCT responsiveness of peripheral blood mononuclear cells (PBMC) to SLE-related nucleosomal histone epitopes in vitro. In patients with lupus, such stimulation induces a strong interferon (IFN)- $\gamma$ synthesis in $\mathrm{CD}^{+} \mathrm{T}$ cells. After AHSCT, however, IFN- $\gamma$ production by $\mathrm{CD}^{+} \mathrm{T}$ cells is completely abrogated. It is noteworthy that $\mathrm{CD} 4^{+} \mathrm{T}$ cells of patients in clinical remission and treated with conventional approaches still exhibit a propensity for IFN- $\gamma$ production under similar conditions [20]. In contrast, a significant upregulation of interleukin (IL)-13 synthesis occurred with post-AHSCT CD $4^{+} \mathrm{T}$ cells. Interestingly, $\mathrm{CD} 4^{+} \mathrm{T}$ cells from healthy individuals did not display this production of IL-13, raising the possibility that clinical remission may not necessarily imply that typical physiological parameters are restored. In total, these data suggest that AHSCT in the context of SLE shifts the adaptive immune response to relevant antigens from a Th1/inflammatory toward a $\mathrm{Th} 2 /$ anti-inflammatory phenotype.

Extrinsic factors, as opposed to intrinsic ones (e.g. $\mathrm{CD} 4^{+} \mathrm{T}$ cell sensitivity/responsiveness to the immunogens) mediated these phenotypic changes of $\mathrm{CD}^{+}$behavior. Indeed, removing $\mathrm{CD} 8^{+} \mathrm{T}$ cells from post-AHSCT PBMC restored the production of IFN- $\gamma$ in $\mathrm{CD}^{+} \mathrm{T}$ cells. In contrast, when post-AHSCT PBMC were stimulated with nucleosomal epitopes in co-culture with $\mathrm{CD} 8^{+} \mathrm{T}$ cells preserved from the pre-AHSCT stage, IFN- $\gamma$ production remained elevated. Hence, AHSCT appears to reconfigure $\mathrm{CD} 8^{+} \mathrm{T}$ cells toward an immunosuppressive phenotype.

The ability of $\mathrm{CD}^{+} \mathrm{T}$ cells to regulate $\mathrm{CD} 4^{+} \mathrm{T}$-cell proliferation in vitro also changed remarkably following AHSCT. Indeed, in the presence of irradiated allogenic antigen-presenting cells, both pre- and post-AHSCT CD4 ${ }^{+}$ $\mathrm{T}$ cells proliferated roughly $30 \%$ more when co-cultured with pre-AHSCT $\mathrm{CD}^{+} \mathrm{T}$ cells compared to control conditions. However, co-culture with post-AHSCT $\mathrm{CD}^{+}$cells inhibited the proliferation of either population of $\mathrm{CD}^{+} \mathrm{T}$ cells by $25 \%$. Interestingly, $\mathrm{CD} 8^{+} \mathrm{T}$ cells from patients treated with conventional therapy neither potentiated nor suppressed $\mathrm{CD}^{+}$proliferation. Finally, whereas proliferation potentiation 
by pre-AHSCT $\mathrm{CD} 8^{+} \mathrm{T}$ cells was mediated through a cell contact dependent mechanism, transforming growth factor (TGF)- $\beta$ and IL-10 produced by post-AHSCT $\mathrm{CD} 8^{+} \mathrm{T}$ cells suppressed $\mathrm{CD}^{+}{ }^{+} \mathrm{T}$-cell proliferation.

The elevated levels of FoxP3 detected in $\mathrm{CD} 8^{+} \mathrm{T}$ cells following AHSCT, along with the ability of post-AHSCT $\mathrm{CD} 8^{+} \mathrm{T}$ cells to produce TGF- $\beta$ and suppress $\mathrm{CD} 4^{+} \mathrm{T}$-cell proliferation and pro-inflammatory activity suggest that a $\mathrm{CD} 8^{\text {TGF- } \beta}$ Treg subset exists within the $\mathrm{CD} 8^{+}$T-cell collective population. Therefore, these $\mathrm{CD} 8^{\mathrm{TGF}-\beta}$ Treg cells through immunomodulatory mechanisms could be critical to clinical remission in SLE following AHSCT. Whether they are relevant to the remission that follows AHSCT in MS is still unknown, but the possibility is interesting in light of a recent report implicating $\mathrm{CD} 8^{+} / \mathrm{CD} 25^{+} / \mathrm{FoxP}^{+} \mathrm{T}$ cells in MS [21].

\section{AHSCT Mechanism of Action: The Immunosuppression Hypothesis}

The observations that immune changes accompany clinical remission following AHSCT are correlative. In addition, evidence corroborates the significant and long-lasting immunosuppressive properties of alemtuzumab or rabbit anti-thymocyte globulin (rATG) that have been predominately used to achieve lymphoablation in AHSCT. Hence, alemtuzumab or rATG may dampen the immune system activity, thus inhibiting its capacity to mount autoreactive responses. Because the alemtuzumab-based therapies are efficient with MS, it adds further support to this hypothesis [22]. Note that because the clinical efficacy of rATG has yet to be demonstrated for MS, this discussion will limit itself to alemtuzumab.

Alemtuzumab, also known as Campath- $1 \mathrm{H}$, targets CD52, a glycoprotein present at the surface of most immune cells, including T-lymphocytes [23-25]. One early report suggested that it is present on more than $95 \%$ of thymocytes [26]. Importantly, however, its expression on CD $34^{+} \mathrm{HSCs}$ is low [27]. Binding of alemtuzumab to CD52 leads to cytotoxicity through different mechanisms, including antibody-mediated cytolysis [28], complement-induced membrane attack complex [29], and apoptosis [30, 31]. The cytolytic effects of alemtuzumab lead to prolonged lymphopenia and a complete reconstitution of T-lymphocyte populations may take as long as 5 years [32].

Characterization of the immune profile in the year following alemtuzumab therapy in MS patients indicated that reconstitution of the different populations of lymphocytes does not evolve at the same rate, and that overall reconstitution proceeds in 2 phases [23]. The early phase occurs during the first 6 months. Initially, trace amounts of $\mathrm{CD} 4^{+}$and $\mathrm{CD} 8^{+}$ cells are detected in the circulation 1 month after the treatment. As T cells start to recover, and until month 3, the proportion of $\mathrm{CD}^{+} / \mathrm{CD} 45 \mathrm{RO}^{+}$memory T cells significantly increases relative to $\mathrm{CD}^{+} / \mathrm{CD}_{4} \mathrm{RA}^{+}$naive $\mathrm{T}$ cells. $\mathrm{CD} 4^{+} /$ $\mathrm{CD} 45^{+} / \mathrm{CD} 25^{\text {high }}$ Tregs largely contribute to this effect; the representation of these cells at 3 and 6 months after alemtuzumab doubled and tripled, respectively, compared to pretreatment levels. In addition, the $\mathrm{CD} 8^{+} \mathrm{T}$-cell population recovers faster than $\mathrm{CD}^{+} \mathrm{T}$ cells in the early phase. Finally, during the late phase $\mathrm{T}$ cells ratios among the different $\mathrm{T}$-cell populations re-equilibrated toward pretreatment levels. Note, however, that absolute cell counts are still decreased 1 year after treatment, with the total $\mathrm{CD}^{+}$and $\mathrm{CD}^{+}$T-cell populations reaching only $32 \%$ and $55 \%$ of the pretreatment levels, respectively.

Changes in T-cell properties are also seen at the individual cell level after alemtuzumab administration [33]. In vitro Tcell proliferative potential is substantially increased 3 months after therapy compared to pretreatment. This occurs both in response to either unstimulated or myelin basic protein exposure conditions. Furthermore, $\mathrm{T}$ cells are also more susceptible to passive and Fas-mediated apoptosis.

Recent evidence suggests that a subset of B cells has an active role in the etiology of MS and may potentiate activity of MS-promoting $T$ cells [34]. Reports that administration of antibody Rituximab, which targets CD20 on B cells, is effective at treating MS corroborate this hypothesis [34, 35]. Interestingly, alemtuzumab also substantially affects B-cell homeostasis, and the reconstitution of these cells contrasts dramatically with that of the T cells [36]. Indeed, by month 3 after an alemtuzumab pulse, B cells have not only reestablished their pretreatment levels, but continue to proliferate massively and reach $165 \%$ of their original pretreatment levels at the 1-year follow-up. This reconstitution is essentially mediated by the generation of immature B cells, as opposed to proliferation of memory B cells.

\section{AHSCT Mechanism of Action: Reconciling Hypothesis}

Nonmyeloablative conditioning regimens followed by AHSCT, alemtuzumab-based therapies and possibly rATGbased therapies all have the potential to significantly improve the prognosis of MS patients. As such, it can be expected that clinical experiments with these therapies in the near future will become less aimed at demonstrating their clinical potential per se, and more focused on 1) the investigation of their therapeutic mechanisms, 2) which category of patients benefits the most from them, and 3) how to minimize side effects. Concerning the molecular and cellular mechanisms involved in the benefit resulting from these therapies, whether the theoretical gap existing between nonmyeloablation followed by AHSCT on the one hand, and the alemtuzumab-based therapies on the 
other, will remain is unclear. Indeed, as both therapies involve lymphoablation, substantial overlap in their physiological effects may exist. The therapeutic effects provided by each approach may arise from a common mechanism, and therefore reconciling hypotheses should be considered. One such hypothesis is that in response to the lymphoablative nature of either therapies, the reconstitution and adaptation of the immune system to the lymphoablative drugs re-programs this system de facto, which then becomes either incapable of mounting MS autoimmune attacks of clinical importance, or self-tolerant.

The extent to which AHSCT leads to an immune reset or reconfiguration is not clear. No consensual operational definition of what "immune reset" exactly represents has been proposed. Hence, the lack of such definition can make the use of the term "reset" misleading, as it entails a return to a default state of immune parameters. In reality, this may not necessarily be the case, and demonstrating that the immune system of an MS patient returns to a prepathological state is technically challenging. Furthermore, and as previously mentioned, there are differences in the phenotype of a post-AHSCT immune system and that of a healthy individual [9]. One possible explanation for this is that the ontology of the post-AHSCT immune system is influenced by internal and external factors that are likely to be markedly different from those typically operating in early life. Indeed, the physiological parameters of an MS patient (e.g., immune cell ratios, metabolism, and so forth) are different from those of the fetal and infancy stages, and the exposure to environmental factors (e.g., pathogenic agents) that can impact immune development are also different [37]. Of note, persisting $\mathrm{T}$ cells also have been detected in patients following either myeloablative or nonmyeloablative conditioning regimen, and these may also influence the development of the reconstituting immune system [38, 39]. Thus, it is not clear at this point whether the immune system is actually "reset" in the true sense of the term. However, the characteristics that the immune system acquires following AHSCT certainly suggest that it has become alternatively programmed.

On the other hand, alemtuzumab does have important effects as previously mentioned on the ratios of different $\mathrm{T}$ cell populations [23]. Thus, the benefits alemtuzumab provides to MS patients may be a consequence of these ratio shifts and not necessarily because T-cell subpopulations to which MS effectors belong are significantly decreased in absolute numbers. Indeed, it is still unknown whether alemtuzumab is effective because the pool of autoreactive $\mathrm{T}$ cells is greatly diminished, or because autoreactive mechanisms are altered by immunoregulatory mechanisms, for example provided by $\mathrm{CD} 4^{+} / \mathrm{CD} 25^{+}$Tregs which recover relatively fast in number. Note also that a combination of both hypotheses is possible. In 2009, Jones and Coles [40] similarly proposed that alterations in the overall immune status and not lymphopenia per se were probably critical for the beneficial effects of alemtuzumab in MS.

The immune system of patients in either therapy likely presents similar characteristics in the aftermath of the lymphoablative conditioning regimen or the alemtuzumab pulse cycle. However, divergences emerge with the transplantation of a graft of HSC, which is free of T-cell clones [41]. For instance, cell numbers appeared to recover more rapidly in the Muraro et al. [16] study in 2005 than in the Cole et al. [22] study in 2008. There also appears to be a higher proportion of patients achieving progression-free survival with AHSCT at a 3-year follow-up, although these are still preliminary results $[8,22]$. Yet, this lays the ground for a fundamental question: How does transplantation of $\mathrm{CD} 34^{+}$ HSCs following a lymphoablative conditioning regimen alter the reconstitution and reprogramming of the immune system?

It is plausible that alemtuzumab modulates lymphoid progenitor niches within the thymus by eliminating lymphoid progenitors from existing niches or by creating novel niches to meet the demands for important proliferation to ensure a prompt return for T-cell homeostasis. Note that these possibilities are not mutually exclusive. These niches will replenish in time through the proliferative activity of residual lymphoid progenitors (blood $\mathrm{CD} 34^{+} \mathrm{HSCs}$ ), and possibly through dedifferentiation of $\mathrm{B}$ cells to uncommitted lymphoid progenitors. The contribution of B cells might be relevant in a context of T-cell lymphopenia, considering the major burst of proliferative activity that they exhibit following depletion and their capacity to dedifferentiate into T-cell progenitors [42]. Among those cellular types, it can be argued that $\mathrm{CD} 34^{+}$HSCs have the highest potential for the reconstitution of a homeostatic, nonautoreactive immune system. Indeed, alemtuzumab-surviving lymphoid progenitors may still possess the capacity to generate MS promoting T-lymphocytes, whereas the ontological and cellular history of B cells could have set epigenetic barriers that incapacitate them from generating a homeostatic immune system. Thus, without transplantation, the competitive advantage possessed by endogenous $\mathrm{CD} 34^{+}$HSCs over the other cellular populations for vacant lymphoid progenitor niches is relatively small as compared to that obtained after transplantation. This may be a key component of the mechanism responsible for the different, although still preliminary, clinical outcomes between AHSCT and alemtuzumab-pulse therapies.

\section{Conclusion}

Despite technical challenges associated with comparing a pre- vs post-AHSCT immune system, the data gathered thus 
far from varied clinical trials yield converging evidence that AHSCT fundamentally modifies the immune system in ways that are hardly possible with lymphoablation per se. This conclusion, along with the increasing expertise that is being developed around the world with AHSCT therapies allows for a cautious optimism for the use of AHSCT in the treatment of MS.

Acknowledgments The Canadian Institutes in Health Research (CIHR), Neuroscience Canada (Brain Repair Program), and the Multiple Sclerosis Society of Canada support this research.

Full conflict of interest disclosure is available in the Electronic Supplementary Material for this article.

Disclosure One author (S.R.) holds a Canadian Research Chair in Neuroimmunology.

Competing Interest The authors declare no competing interests.

\section{Appendix}

\section{Box 1: Improving AHSCT to treat MS}

Although lymphoablative conditioning regimens are safer than myeloablative ones, they still may pose significant health issues. For instance, development of secondary autoimmune diseases can occur following lymphoablation [43], and few cases of autoimmune thrombocytopenia occurred in the study by Burt et al. [8]. To address this issue and decrease the risks of developing secondary autoimmune diseases, rabbit anti-thymocyte globulin (rATG) has now largely replaced alemtuzumab to achieve lymphoablation [8, 44], although this does not completely eliminate the risk to develop secondary autoimmune diseases. Note that rATG administration also appears to significantly alter and/or reprogram the immune system [45].

Finally, as more and more data regarding the different immunological profiles of pre- vs post-autologous hematopoietic stem cell transplantation (AHSCT) therapy are gathered, it is conceivable that they will eventually be used to predict probabilities of remission and anticipate relapses and/or complications. Hence, these data will allow for more efficient treatment management, which should further improve the health condition of multiple sclerosis (MS) patients.

\section{Box 2: Transplantation of Bone Marrow Mesenchymal Stem Cells}

A different transplantation strategy for the treatment of multiple sclerosis (MS) consists of the infusion of autologous mesenchymal stem cells, either intravenously or intrathecally, and/or intracisternally. A primary aim of this strategy is to promote the activity of neuronal and myelin repair mechanisms to restore central nervous system functions, although this procedure also has non-negligible immune-modulatory effects. However, because no myeloablation or lymphoablation is performed with this type of therapy, it does not allow for the elimination of the pathological immune system.

\section{References}

1. Voltarelli JC, Couri CE, Stracieri AB, et al. Autologous nonmyeloablative hematopoietic stem cell transplantation in newly diagnosed type 1 diabetes mellitus. JAMA 2007;297:1568-1576.

2. Traynor AE, Schroeder J, Rosa RM, et al. Treatment of severe systemic lupus erythematosus with high-dose chemotherapy and haemopoietic stem-cell transplantation: a phase I study. Lancet 2000;356:701-707.

3. Burt RK, Traynor A, Ramsey-Goldman R. Hematopoietic stemcell transplantation for systemic lupus erythematosus. N Engl J Med 1997;337:1777-1778.

4. Tyndall A, Black C, Finke J, et al. Treatment of systemic sclerosis with autologous haemopoietic stem cell transplantation. Lancet 1997;349:254.

5. Burt RK, Abinun M, Farge-Bancel D, et al. Risks of immune system treatments. Science 2010;328:825-826.

6. Rogojan C, Frederiksen JL. Hematopoietic stem cell transplantation in multiple sclerosis. Acta Neurol Scand 2009;120:371-382.

7. Hamerschlak N, Rodrigues M, Moraes DA, et al. Brazilian experience with two conditioning regimens in patients with multiple sclerosis: BEAM/horse ATG and CY/rabbit ATG. Bone Marrow Transplant 2010;45:239-248.

8. Burt RK, Loh Y, Cohen B, et al. Autologous non-myeloablative haemopoietic stem cell transplantation in relapsing-remitting multiple sclerosis: a phase I/II study. Lancet Neurol 2009;8:244-253.

9. Zhang L, Bertucci AM, Ramsey-Goldman R, Burt RK, Datta SK. Regulatory $\mathrm{T}$ cell (Treg) subsets return in patients with refractory lupus following stem cell transplantation, and TGF-betaproducing CD8+ Treg cells are associated with immunological remission of lupus. J Immunol 2009;183:6346-6358.

10. Kotzin BL. Systemic lupus erythematosus. Cell 1996;85:303-306.

11. Rahman A, Isenberg DA. Systemic lupus erythematosus. N Engl J Med 2008;358:929-939.

12. Datta SK. Major peptide autoepitopes for nucleosome-centered $T$ and B cell interaction in human and murine lupus. Ann N Y Acad Sci 2003;987:79-90.

13. Stangel M. Multiple sclerosis: Hematopoietic stem cell transplantation: hope and hype. Nat Rev Neurol 2009;5:300-302.

14. Mancardi G, Saccardi R. Autologous haematopoietic stem-cell transplantation in multiple sclerosis. Lancet Neurol 2008;7:626636.

15. Capello E, Vuolo L, Gualandi F, et al. Autologous haematopoietic stem-cell transplantation in multiple sclerosis: benefits and risks. Neurol Sci 2009;30(suppl 2):S175-S177.

16. Muraro PA, Douek DC, Packer A, et al. Thymic output generates a new and diverse TCR repertoire after autologous stem cell transplantation in multiple sclerosis patients. J Exp Med 2005;201:805-816.

17. Goronzy JJ, Weyand CM. T cell development and receptor diversity during aging. Curr Opin Immunol 2005;17:468-475.

18. Alexander T, Thiel A, Rosen O, et al. Depletion of autoreactive immunologic memory followed by autologous hematopoietic stem cell transplantation in patients with refractory SLE induces longterm remission through de novo generation of a juvenile and tolerant immune system. Blood 2009;113:214-223. 
19. Sun W, Popat U, Hutton G, et al. Characteristics of T-cell receptor repertoire and myelin-reactive $\mathrm{T}$ cells reconstituted from autologous haematopoietic stem-cell grafts in multiple sclerosis. Brain 2004;127:996-1008.

20. Lu L, Kaliyaperumal A, Boumpas DT, Datta SK. Major peptide autoepitopes for nucleosome-specific T cells of human lupus. J Clin Invest 1999;104:345-355.

21. Correale J, Villa A. Role of CD $8+\mathrm{CD} 25+$ Foxp3 + regulatory $\mathrm{T}$ cells in multiple sclerosis. Ann Neurol 67:625-638.

22. Coles AJ, Compston DA, Selmaj KW, et al. Alemtuzumab vs. interferon beta-1a in early multiple sclerosis. N Engl J Med 2008;359:1786-1801.

23. Cox AL, Thompson SA, Jones JL, et al. Lymphocyte homeostasis following therapeutic lymphocyte depletion in multiple sclerosis. Eur J Immunol 2005;35:3332-3342.

24. Ambrose LR, Morel AS, Warrens AN. Neutrophils express CD52 and exhibit complement-mediated lysis in the presence of alemtuzumab. Blood 2009;114:3052-3055.

25. Ratzinger G, Reagan JL, Heller G, Busam KJ, Young JW. Differential CD52 expression by distinct myeloid dendritic cell subsets: implications for alemtuzumab activity at the level of antigen presentation in allogeneic graft-host interactions in transplantation. Blood 2003;101:1422-1429.

26. Hale G, Bright S, Chumbley G, et al. Removal of T cells from bone marrow for transplantation: a monoclonal antilymphocyte antibody that fixes human complement. Blood 1983;62:873882.

27. Klabusay M, Sukova V, Coupek P, Brychtova Y, Mayer J. Different levels of CD52 antigen expression evaluated by quantitative fluorescence cytometry are detected on Blymphocytes, CD $34+$ cells and tumor cells of patients with chronic B-cell lymphoproliferative diseases. Cytometry B Clin Cytom 2007;72:363-370.

28. Xia MQ, Tone M, Packman L, Hale G, Waldmann H. Characterization of the CAMPATH-1 (CDw52) antigen: biochemical analysis and cDNA cloning reveal an unusually small peptide backbone. Eur J Immunol 1991;21:1677-1684.

29. Xia MQ, Hale G, Lifely MR, et al. Structure of the CAMPATH-1 antigen, a glycosylphosphatidylinositol-anchored glycoprotein which is an exceptionally good target for complement lysis. Biochem J 1993;293(part 3):633-640.

30. Nuckel H, Frey UH, Roth A, Duhrsen U, Siffert W. Alemtuzumab induces enhanced apoptosis in vitro in B-cells from patients with chronic lymphocytic leukemia by antibody-dependent cellular cytotoxicity. Eur J Pharmacol 2005;514:217-224.

31. Stanglmaier M, Reis S, Hallek M. Rituximab and alemtuzumab induce a nonclassic, caspase-independent apoptotic pathway in Blymphoid cell lines and in chronic lymphocytic leukemia cells. Ann Hematol 2004;83:634-645.
32. Coles AJ, Cox A, Le Page E, et al. The window of therapeutic opportunity in multiple sclerosis: evidence from monoclonal antibody therapy. J Neurol 2006;253:98-108.

33. Jones JL, Phuah CL, Cox AL, et al. Coles. IL-21 drives secondary autoimmunity in patients with multiple sclerosis, following therapeutic lymphocyte depletion with alemtuzumab (Campath-1H). J Clin Invest 2009;119:2052-2061.

34. Bar-Or, A., L. Fawaz, B. Fan, P.J. Darlington, A. Rieger, C. Ghorayeb, P.A. Calabresi, E. Waubant, S.L. Hauser, J. Zhang, and C.H. Smith. Abnormal B-cell cytokine responses a trigger of Tcell-mediated disease in MS? Ann Neurol 67:452-461.

35. Naismith RT, Piccio L, Lyons JA, et al. Rituximab add-on therapy for breakthrough relapsing multiple sclerosis: a 52-week phase II trial. Neurology 74:1860-1867.

36. Thompson SA, Jones JL, Cox AL, Compston DA, Coles AJ. Bcell reconstitution and BAFF after alemtuzumab (Campath-1H) treatment of multiple sclerosis. J Clin Immunol 2010;30:99-105.

37. Nash RA, Dansey R, Storek J, et al. Epstein-Barr virus-associated posttransplantation lymphoproliferative disorder after high-dose immunosuppressive therapy and autologous CD34-selected hematopoietic stem cell transplantation for severe autoimmune diseases. Biol Blood Marrow Transplant 2003;9:583-591.

38. Mondria T, Lamers CH, te Boekhorst PA, Gratama JW, Hintzen RQ. Bone-marrow transplantation fails to halt intrathecal lymphocyte activation in multiple sclerosis. J Neurol Neurosurg Psychiatry 2008;79:1013-1015.

39. Storek J, Zhao Z, Liu Y, Nash R, McSweeney P, Maloney DG. Early recovery of CD4 T cell receptor diversity after "lymphoablative" conditioning and autologous CD34 cell transplantation. Biol Blood Marrow Transplant 2008;14:1373-1379.

40. Jones JL, Coles AJ. Spotlight on alemtuzumab. Int MS J 2009;16:77-81.

41. Dubinsky AN, Burt RK, Martin R, Muraro PA. T-cell clones persisting in the circulation after autologous hematopoietic SCT are undetectable in the peripheral CD34+ selected graft. Bone Marrow Transplant 45:325-331.

42. Cobaleda C, Jochum W, Busslinger M. Conversion of mature B cells into $\mathrm{T}$ cells by dedifferentiation to uncommitted progenitors. Nature 2007;449:473-477.

43. Loh Y, Oyama Y, Statkute L, et al. Development of a secondary autoimmune disorder after hematopoietic stem cell transplantation for autoimmune diseases: role of conditioning regimen used. Blood 2007;109:2643-2548.

44. Muraro PA, Abrahamsson SV. Resetting autoimmunity in the nervous system: The role of hematopoietic stem cell transplantation. Curr Opin Investig Drugs 2010;11:1265-1275.

45. Gurkan S, Luan Y, Dhillon N, et al. Murphy. Immune reconstitution following rabbit antithymocyte globulin. Am J Transplant 10:21322141. 